\title{
Prehospital care of head injured patients
}

\author{
Hari H. Dash \\ Department of Neuroanesthesiology, Neurosciences Centre, All India Institute of Medical Sciences, New Delhi, India
}

\begin{abstract}
Resuscitation of head injured patients at the accident site is paramount in minimizing morbidity and mortality. This can be achieved through prehospital care which is nonexistent in our country. This review is a step forward, so that we can formulate guidelines in this regard.
\end{abstract}

Key words: Head injury, prehospital care, controversies, prevention

Head injury afflicts millions of people throughout the world each year. Mortality following head injury has been reported in the range of $39-51 \% \cdot{ }^{[1,2]}$ Majority of the patients are in the prime of their lives. Those who do not succumb are often permanently disabled incurring staggering societal costs for rehabilitation, long-term care, and loss of productivity. As automobile accidents account for the majority of trauma, the problem will worsen on a worldwide scale as vehicles becomes more widespread in developing countries. ${ }^{[3]}$ In Mexico, the mortality rate from motor vehicle-related trauma has increased steadily over the past 20 to 30 years, to the point where it is one of the leading causes of death in children and young adults. ${ }^{[4]}$ To combat this menace, trauma care team supervised by emergency physicians have seen a decline in functional neurological outcome. ${ }^{[5,6]}$ In England and Wales the treatment of head injured patients in a neurosurgical center represents an important strategy in the management of severe head injury which was responsible in achieving better neurological recovery or decrease in the rate of mortality. ${ }^{[7]}$

The dawn of a new era occurs as the paradigm for the treatment of patients with head injury is changing. An explosion of research has driven this paradigm shift on the better understanding of the physiological and biochemical cascades that set in immediately after head trauma, and pathophysiology of the injured brain.

\section{Pathophysiological and Biochemical Changes Following Head Injury}

The realization of the critical phase of head injury is arbitrarily defined as the first $10 \mathrm{~min}$ after the onset of head trauma. Two immediate physiological and biochemical events occur soon after head trauma that substantially affect subsequent outcome; head injury induces apnea and stress-related massive sympathetic discharge. ${ }^{[8]}$ This was supplemented by the awareness of the role of ischemia in first $24 \mathrm{~h}$ following head injury, which is commonly known as secondary injury. New insights into the mechanisms of cerebral edema and ischemic brain injury led to an understanding of secondary injury which may manifest within minutes or hours after the primary insult. ${ }^{[9,10]}$

\section{Why Prephospital Care?}

The staggering morbidity and mortality of severe head injury could remarkably be reduced by simply securing and maintaining the airway and providing ventilation to such patients at the accident scene. ${ }^{[3]}$ When this measure was undertaken, $90 \%$ mortality rate in these patients was dramatically decreased to $40 \%{ }^{[11]}$ Morbidity and mortality in these patients has declined during the past decade due to improvement in the prehospital care. This also facilitates timely medical and surgical intervention. ${ }^{[12,13]}$

\section{Prehospital Care in Developed vs. Developing Countries}

Even when neurosurgical trauma care and patient outcome are compared in countries as medically diverse as the US and India, timely care in the field and expeditious transport to trauma centers are the most important criteria separating the morbidity and mortality statistics of head injuries in the US and India. ${ }^{[14]}$ Increase in sites of ambulance dispatch and 
increased training in Prehospital Trauma Life Support (PHTLS) course to the paramedics improved the process of prehospital care in LatinAmerica City and resulted in decrease in prehospital deaths. ${ }^{[15]}$

\section{Goals of Prehospital Care}

The prehospital phase seems to be the most critical period during which the imperative is to prevent secondary brain damage after head trauma. ${ }^{[9]}$ The strategies that have to be undertaken are:

1. immediate care of the airway and breathing.

2. prompt restoration and maintenance of hemodynamic stability.

3. provide optimal environment for the brain by taking care of intracranial pressure (ICP).

4. take adequate and proper care of associated injuries.

5. transport the patient to the most appropriate multidisciplinary hospital.

\section{Initial Assessment and Care}

First assess the severity of the injury and find out whether the patient has sustained penetrating or blunt trauma to head. If the injury is a penetrating injury then one should try to stop the bleeding by compressive bandage or sterile packing of the wound.

\section{Extrication}

Head neck collars for spinal protection are mandatory in unconscious patients, especially during extrication. Both scoop-stretchers and spinal boards with foam head restraints are established methods for spinal protection. But, it may be prudent to use a vacuum mattress as an alternative during transportation.

\section{Institution of Advanced Life Support}

Two basic physiological derangements so negatively affect the outcome of brain injured patients that they should be assessed during the prehospital phase and corrected immediately. Hypoxemia and hypotension, are strongly associated with poor outcome. ${ }^{[16,17]}$ Therefore, it is highly essential to institute ABC (i.e., Airway, Breathing, Circulation) of advanced life support (ALS) as early as possible. ${ }^{[18]}$

\section{Indications of Intubation}

(1) coma (GCS $<8$ ), (2) loss of protective reflexes, (3) ventilatory insufficiency, (4) spontaneous hyperventilation, (5) bilateral fracture mandible, (6) copious bleeding into oral cavity, (7) pulmonary edema, and (8) seizure.

\section{Initial Management}

Administration of $\mathrm{O}_{2}$ by mask and intravenous infusion of normal saline through a wide bore cannula must precede the attempts of intubation.

\section{Techniques of Securing Airway}

Although the cough reflex may be obtunded in severe head injured patients, it may be normal even in patients with GCS of 3. Endotracheal intubation attempts may fail and cause vomiting, aspiration and dangerous increase in ICP. Rapid sequence induction along with properly applied manual inline stabilization followed by orotracheal intubation has been found to be safe in patients with cervical spine injury. ${ }^{[19]}$ In children, input by experienced intubators (anesthetists) would be of obvious benefit. In the face of failed intubation, bag-valve-mask ventilation must be continued. Use of laryngeal mask airway (LMA) and the oesophageal tracheal Combitube are good alternatives. Cricothyroidotomy should be considered as a last resort.

Ventilation should be continued by using a volume preset portable ventilator. Tidal volume should be maintained around $10-12 \mathrm{ml} / \mathrm{kg}$ with a respiratory rate of $10-12 / \mathrm{min}$ so that both hypo and hyperventilation are avoided.

\section{Use of Anesthetic Drugs}

Various induction agents, such as etomidate, thiopentone, propofol and midazolam have been used. Fentanyl 1-2 microgram $/ \mathrm{kg}$ seems to be the preferred opioid. These induction agents all carry an obvious risk of de-masking hypovolemia and inducing dangerous hypotension. Hence, when used, they must be used in reduced and carefully titrated doses. In patients with obvious signs of hemodynamic compromise, they are often better omitted.

Ketamine is a well-established anesthetic for field use. It may be a suitable agent for induction of anesthesia in patients with cardiovascular compromise or instability. ${ }^{[20]}$ Recent clinical trials have shown that it does not increase ICP and cerebral blood flow velocity. ${ }^{[21,22]}$ The intubation dose of succinylcholine should be followed by a non-depolarizing neuromuscular blocker. Highdose rocuronium $(0.9 \mathrm{mg} / \mathrm{kg})$ may achieve excellent intubating conditions within $60 \mathrm{sec}$.

\section{Fluid Resuscitation}

Infusion of normal saline is recommended as it is isotonic. Despite infusing intravenous fluids if blood pressure (BP) remains low, then one should resort to colloids and lastly vasopressors. Administration of glucose-containing fluids is contraindicated in the prehospital phase. It may aggravate ischemia and brain edema. Small volume resuscitation is a promising concept for the treatment of hypovolemia. ${ }^{[23]} \mathrm{A}$ large 
multicenter randomized double-blind controlled study compared 7.5\% hypertonic saline and Ringer's lactate for prehospital resuscitation in patients of severe head injury with hypotension. In this study, the investigators observed almost identical neurological functions in their patients, 6 months after injury. ${ }^{[24]}$ A recently concluded SAFE trial had observed increase in mortality in those patients who received albumin for resuscitation following head injury ${ }^{[25]}$ Small volume $(250 \mathrm{ml})$ Ringer's lactate or normal saline infusion to correct hypotension is efficacious.

\section{Use of Vasopressors}

Dopamine, as a vasopressor is very popular amongst physicians. The major disadvantages of dopamine however, are tachycardia, aggravation of brain edema and it may suppress anterior pituitary hormones. ${ }^{[26]}$ Infusion of noradrenaline has been found to increase brain tissue oxygenation along with augmentation of cerebral perfusion pressure in head injury patients. ${ }^{[27,28]}$ Therefore, it is prudent to use low-dose noradrenaline to combat hypotension

\section{Monitoring}

Continuous monitoring of ECG, heart rate, BP, SpO2 has become an integral part of the prehospital care. ${ }^{[29]}$ End tidal carbon dioxide $\left(\mathrm{EtCO}_{2}\right)$ color indicators and capnography are useful and make it easier to adjust ventilation. ${ }^{[30]}$ Airway pressure monitoring is another useful tool in the prehospital setup. Airway pressure increase is a warning sign of main stem intubation or secretions or development of hemothorax or simply the patient may be fighting the ventilator. Core temperature monitoring is very vital in a patient with head trauma. Mild hypothermia may be beneficial.

\section{Assess Disability}

After evaluation and institution of basic resuscitative measures (ABC of ALS) a detailed neurological assessment must be undertaken. The Glasgow Coma Scale (GCS) has withstood many challenges as a result of its simplicity and widespread acceptance. It is used worldwide for assessing the neurological status of the patient following head injury.

\section{Evaluation and Care of Other Injuries}

Once hemodynamic stability has been achieved then look for other injuries like chest, pelvis, fracture of long bones and abdominal trauma. Early splinting of long bone fractures reduces bleeding and tissue injury. A combination of tight compressive dressing and elevation of the injured extremity should be used. In presence of decreased breath sounds on auscultation one should suspect hemopneumothorax and thoracocentesis may be attempted.

\section{Ongoing Assessment}

This is very important for monitoring and guiding the care you provide. It is performed every $5 \mathrm{~min}$ in comatose and every $15 \mathrm{~min}$ in other patients. Assessment of mental status, cardio-respiratory parameter and muscle tone should be undertaken. Any deterioration of neurological status not attributable to associated injuries along with hemodynamic disturbances may denote impending transtentorial herniation which must be identified and managed with mannitol immediately.

\section{Accident Site}

"Safety first" should be the primary concern when approaching an accident scene. Information about potential hazards to rescue personnel and patients should be obtained. Personnel who are accustomed to working in the prehospital arena should also lead the medical rescue work in mass casualty situations. It is imperative to know and respect the role of the other professionals at the scene.

\section{Hazardous Material and Toxic Fumes}

Prehospital medical responders must be familiar with the risk and understand the protocols for dealing with casualties of accidental toxic release. HAZMAT (hazardous material) is an acronym for toxic chemicals. In a HAZMAT accident, the incident commander is usually a fire officer. Emergency medical service (EMS) teams must understand the need to liaise with the fire service, protect themselves, and prevent secondary casualties and the spread of contamination. The respiratory system is most vulnerable with the fumes and gases. Many toxic substances also cause cardiac dysrhythmias. ${ }^{[13]}$

\section{Transportation}

Use of ambulance helicopters have been preferred in advanced countries as it may reduce the time to initial assessment, treatment, and definitive hospital treatment. However, ground transportation may be more time-efficient in areas close to the receiving hospital. Optimal evacuation requires choosing the right patient at the right time and using the right means of transportation to the right hospital.

\section{Indian Roads}

The traffic scenario in India, however, is totally different. Lanes have been marked for the movement of single automobile. But they remain clogged with different types of vehicles thus hindering rapid movement of ambulance or emergency vehicles. Public 
awareness campaigns pertaining to lane driving and allowing ambulance first should be launched to educate the drivers and motorists. Neurotrauma or Trauma Society of India should organize such public awareness programs and regular workshops for the traffic police so that prehospital care of head injured patients can be achieved. Increase in the sites of ambulance dispatch (one ambulance to cover a distance of $5 \mathrm{~km}$ ) will augment the transfer of patients to an appropriate hospital. ${ }^{[15]}$ Regular training program on Prehospital Transportation Life Support course should be carried out for the benefit of paramedics and traffic police. Use of ambulance helicopter service for rapid evacuation of head injured victims though sounds impossible, is not a distant dream to achieve for our highways and for the metros.

\section{Controversies}

The age-old concepts of management of head injured patients in the prehospital setup have recently been challenged. Following are the controversies:

\section{Anesthetists vs. Paramedics}

Anesthetists can be ideal trauma life support physicians because they can take proper care of the airway, have practical experience, and can use neuromuscular blocking drugs and induction agents. Their experience and expertise is of immense help in the management of pediatric head trauma. Recently, however, Di Bartolomeo et al., have failed to demonstrate any outcome benefit brought about by a combined ALS, physician-led, and rotorcraft-flown prehospital team. ${ }^{[31]}$

\section{Prehospital vs. Hospital Intubation}

Immediate endotracheal intubation and ventilation in the head injured patients have shown to improve survival. ${ }^{[19]}$ In a retrospective study, Murray et al., had observed no improvement in survival in prehospital intubated patients in comparison to patients who were intubated on arrival in the hospital. ${ }^{[32]}$ Recently, Bochicchio et al., carried out a prospective study in 191 consecutive patients and concluded that prehospital intubation is associated with a significant increase in morbidity and mortality in patients with traumatic brain injury. ${ }^{[33]}$ Similar observations have also been reported in pediatric trauma victims. ${ }^{[34]}$

\section{Hyperventilation}

Though hyperventilation has not been recommended in the first $24 \mathrm{~h}$ in severe head injury, the practice still continues. ${ }^{[35]}$ Further research in this field encompassing a large number of patients will unravel the proper evidence-based management.

\section{Prevention}

The doctrine "prevention is better than cure" is most appropriate for head injured patients. This can be achieved by enforcing the use of a helmet by twowheeler riders in our country. There should not be any distinction on the basis of fair sex or religion as road traffic accidents do not distinguish between persons on these grounds. Roadside hidden cameras are of great help to book speed violators. Regular breath tests at appropriate locations to catch drunken drivers will go a long way in preventing road accidents. Also strict and stringent driving licensing system should be adopted so that only properly trained drivers are allowed to use the roads.

\section{Conclusion}

We must begin efforts to improve prehospital care, as it is the most critical phase of head injury. If we respond to head injury as rapidly as possible and begin treatment as early as possible, perhaps the morbidity and mortality associated with head injury will be reduced to a level not yet achieved. Research in prehospital care is needed and should include inputs from paramedics. The old maxims of "stay and play" and "load and go" or "scoop and run" could perhaps be replaced with "play while running" to the most appropriate hospital. That way we might be able to make a real quantifiable difference.

\section{References}

1. Lannoo E, Van Rietvelde F, Colardyn F, Lemmerling M, Vandekerckhove T, Jannes C, et al. Early predictors of mortality and morbidity after severe closed head injury. J Neurotrauma 2000;17:403-14.

2. Bulger EM, Nathens AB, Rivara FP, Moore M, Mackenzie EJ, Jurkovich GJ. Brain Trauma Foundation: Management of severe head injury: Institutional variations in care and effect on outcome. Crit Care Med 2002;30:1870-6.

3. Barbaccia JJ, Williams JM. The acute management of head injury. Curr Opin Anaesthesiol 2001;14:227-31.

4. Smith GS, Barss P. Unintentional injuries in developing countries: The epidemiology of a neglected problem. Epidemiol Rev 1991;13:228-66.

5. Myburgh JA, Cooper DJ, Finfer SR, Venkatesh B, Jones D, Higgins A, et al. Epidemiology and 12 month outcomes from traumatic brain injury in Australia and New Zealand. J Trauma 2008;64:854-62.

6. Klemen P, Grmec S. Effect of pre-hospital advanced life support with rapid sequence intubation on outcome of severe traumatic brain injury. Acta Anaesthesiol Scand 2006;50:1250-4.

7. Patel HC, Bouamra O, Woodford M, King AT, Yates DW, Lecky FE, et $a l$. Trends in head injury outcome from 1989 to 2003 and the effect of neurosurgical care: An observational study. Lancet 2005;366:1538-44.

8. Atkinson JL. The neglected prehospital phase of head injury: Apnea and catecholamine surge. Mayo Clin Proc 2000;75:37-47.

9. Robertson CS. Management of cerebral perfusion pressure after traumatic brain injury. Anesthesiology 2001;95:1513-7.

10. Andrews PJ, Sleeman DH, Statham PF, McQuatt A, Corruble V, Jones PA, et al. Predicting recovery in patients suffering from traumatic brain injury by using admission variables and physiological data: A comparison between decision tree analysis and logistic regression. J Neurosurg 2002;97:326-36. 
11. Klauber MR, Marshall LF, Toole BM, Knowlton SL, Bowers SA. Cause of decline in head injury mortality rate in San Diego County, California. J Neurosurg 1985;62:528-31.

12. Baker A.J. Management of the severely head injured patient. Can J Anaesth 1999;46:R35-45.

13. Soreide E, Deakin C, Baker D. Prehospital trauma management for the anesthesiologist. Anesthesiol Clin North Ama 1999;17:33-44.

14. Colohan AR, Alves WM, Gross CR, Torner JC, Mehta VS, Tandon PN, et al. Head injury mortality in two centers with different emergency medical services and intensive care. J Neurosurg 1989;71:202-7.

15. Arreola-Risa C, Mock CN, Lojero-Wheatly L, de la Cruz O, Garcia C, Canavati-Ayub F, et al. Low cost improvements in prehospital trauma care in a Latin American city. J Trauma 2000;48:119-24.

16. Procaccio F, Stocchetti N, Citerio G, Berardino M, Beretta L, Della Corte F, et al. Guidelines for the treatment of adults with severe head trauma (part I): Initial assessment; evaluation and pre-hospital treatment; current criteria for hospital admission; systemic and cerebral monitoring. J Neurosurg Sci 2000;44:1-10.

17. The Brain Trauma Foundation. The American Association of Neurological Surgeons. The Joint Section on Neurotrauma and Critical Care. Initial management. J Neurotrauma 2000;17:463-9.

18. Winchell RJ, Hoyt DB. Endotracheal intubation in the field improves survival in patients with severe head injury: Trauma Research and Education Foundation of San Diego. Arch Surg 1997;132:592-7.

19. Sloane C, Vilke GM, Chan TC, Hayden SR, Hoyt DB, Rosen P. Rapid sequence intubation in the field versus hospital in trauma patients. J Emerg Med 2000;19:259-64.

20. Sehdev RS, Symmons DA, Kindl K. Ketamine for rapid sequence induction in patients with head injury in the emergency department. Emerg Med Australas 2006;18:37-44.

21. Himmelseher S, Durieux ME. Revising a dogma: Ketamine for patients with neurosurgical injury? Anesth Analg 2005;101:524-34.

22. Bourgoin A, Albanèse J, Lèone M, Sampol-Manos E, Viviand X, Martin C. Effects of Sufentanil or Ketamine administered in target-controlled infusion on the cerebral hemodynamics of severely brain-injured patients. Crit Care Med 2005;33:1109-13

23. Brasel KJ, Bulger E, Cook AJ, Morrison LJ, Newgard CD, Tisherman $\mathrm{SA}$, et al. Hypertonic resuscitation: Design and implementation of a prehospital intervention trial. J Am Coll Surg 2008;206:220-32.

24. Cooper DJ, Myles PS, McDermott FT, Murray LJ, Laidlaw J, Cooper G, et al. Prehospital hypertonic resuscitation of patients with hypotension and severe traumatic brain injury: A randomized controlled trial. JAMA
2004;291:1350-7.

25. Myburgh J, Cooper DJ, Finfer S, Bellomo R, Norton R, Bishop N, et al. Saline or albumin for fluid resuscitation in patients with traumatic brain injury. N Eng J Med 2007;357:874-84.

26. Pfister D, Strebel SP, Steiner LA. Effects of catecholamines on cerebral blood vessels in patients with traumatic brain injury. Eur J Anaesthesiol (Suppl) 2008;42:98-103.

27. Steiner LA, Johnston AJ, Czosnyka M, Chatfield DA, Salvador $\mathrm{R}$, Coles JP, et al. Direct comparison of cerebrovascular effects of norepinephrine and dopamine in head-injured patients. Crit Care Med 2004;32:1049-54.

28. Johnston AJ, Steiner LA, Coles JP, Chatfield DA, Fryer TD, Smielewski $\mathrm{P}$, et al. Effect of cerebral perfusion pressure augmentation on regional oxygenation and metabolism after head injury. Crit Care Med 2005;33:189-95.

29. Hlatky R, Robertson CS. Multimodality monitoring in severe head injury. Curr Opin Anaesthesiol 2002;15:489-93.

30. Helm M, Schuster R, Hauke J, Lampl L. Tight control of prehospital ventilation by capnography in major trauma victims. $\mathrm{Br} \mathrm{J}$ Anaesth 2003;90:327-32

31. Di Bartolomeo S, Sanson G, Nardi G, Scian F, Michelutto V, Lattuada L. Effect of 2 patterns of prehospital care on the outcome of patients with severe head injury. Arch Surg 2001;136:1293-300.

32. Murray JA, Demetriades D, Berne TV, Stratton SJ, Cryer HG, Bongard F, et al. Prehospital intubation in patients with severe head injury. J Trauma 2000;49:1065-70.

33. Bochicchio GV, Ilahi O, Joshi M, Bochicchio K, Scalea TM. Endotracheal intubation in the field does not improve outcome in trauma patients who present without an acutely lethal traumatic brain injury. J Trauma 2003;54:307-11.

34. Gausche M, Lewis RJ, Stratton SJ, Haynes BE, Gunter CS, Goodrich SM, et al. Effect of out of hospital pediatric endotracheal intubation on survival and neurological outcome: A controlled clinical trial. JAMA 2000;283:783-90.

35. Thomas SH, Orf J, Wedel SK, Conn AK. Hyperventilation in traumatic brain injury patients: Inconsistency between consensus guidelines and clinical practice. J Trauma 2002;52:47-53.

Accepted on 29-07-2008

Source of Support: Nil, Conflict of Interest: None declared. 